\title{
Non- Pharmacological Measures For Control of Hypertension in Geriatric Population
}

\author{
Debalina Sahoo ${ }^{1}$, Harshida Gosai ${ }^{2}$, Ujjwal Sahoo $^{3}$, J.M. Harsoda ${ }^{4}$
}

\begin{abstract}
Background: Increased prevalence of hypertension in all over the world is well recognized. Hypertension affects almost all body organs and systems. It can be managed by using nonpharmacological measures as well. Objective: To assess knowledge of non-pharmacological measures to control of hypertension and its application in geriatric hypertensive population. Methods: The study was conducted in the Department of Physiology, Sumandeep Vidyapeeth University, Vadodara. Total 108 hypertensive patients had been included for this study. Subjects were administered pre tested ten questionnaires. They responded the questionnaires at the same time, without any discussion. Results: Knowledge about normal level of blood pressure was lacking in $70 \%$ of study population. Conclusion: Knowledge about weight reduction, regular exercise, fruits and vegetables intake was poor. About half of the study population said that blood pressure can be controlled by using of drugs only. So, they were not aware of non-pharmacological measures.
\end{abstract}

Key Words: Hypertension, knowledge, exercise, geriatric, population.

Bangladesh Soc Physiol. 2014, December; 9(2): 94-97

For Authors Affiliation, see end of text.

http://www.banglajol.info/index.php/JBSP

\section{Introduction}

$\mathbf{H}$ ypertension is not a chronic disease, but it is independently associated with cardiovascular diseases in the elderly. Although it constitutes one of the most frequent factors for cerebrovascular diseases, it is an amendable to modifications ${ }^{1-3}$ Hypertension (HTN) is a major public health problem in many parts of the world. ${ }^{4-5}$ It is known as "The silent killer", it may exist for prolonged periods without symptoms and may manifest only after causing serious complications. It has been identified as the most common, most potent and most universal contributor to cardiovascular mortality, which accounts for $20-50 \%$ of all deaths. ${ }^{6}$ It is the first sign of a chronic progressive process

Received March 2014; $\quad$ Accepted September 2014 that may end in serious and potentially fatal complications such as stroke or renal failure and it is a major risk factor of coronary artery disease ${ }^{7}$. Untreated hypertension is usually associated with a progressive rise in blood pressure. The vascular and renal damage this state may culminate in a treatment-resistant state. High blood pressure, or hypertension, forces hearts to work harder when pumping blood into our arteries (blood vessels), which can damage the blood vessels in our brain and lead to a stroke. In other cases, hypertension could contribute to hardening of the arteries (atherosclerosis), which can lead to heart failure. Nobody knows the specific cause of high blood pressure, but contributing factors have included stress, genetics, and smoking, drinking too much alcohol, and consuming too much sodium. In the 
world raised blood pressure is estimated to cause 7.5 million deaths, about $12.8 \%$ of the total of all annual deaths. Raised blood pressure is a major risk factor for coronary heart disease and haemorrhagic stroke. In some age groups, the risk of cardiovascular disease doubles because it is progressively related to the risk for stroke and coronary heart disease. In addition to coronary heart diseases and stroke, complications of raised blood pressure include heart failure, peripheral vascular disease, renal impairment, retinal hemorrhage and visual impairment. Blood pressure can be controlled not only with drugs but also non-pharmacological management like exercise, weight reduction, salt restriction, eating fruits and vegetables, etc. Nonpharmacological measures play an important role in management of hypertension. The present study was done to assess knowledge of non pharmacological measures to control hypertension and its application in geriatric hypertensive population.

\section{Methods}

It is a Cross-sectional, questionnaire based study. 120 subjects more than 50 years of age of either gender with history of hypertension were included and persons not willing to participate and/or not giving consent were excluded from the study. The aim and benefit of this study was explained to the respondents and informed consent was obtained from them. A Questionnaire was prepared consisting of 10 questions in a local language (Gujarati) contain questions to assess knowledge, attitude and practice of the persons about non-pharmacological measures to control hypertension. Answer was given in yes/no or in a single sentenced.

Blood pressure was measured in all the participating subjects by sphygmomanometer (GB120) and stethoscope. Data was analyzed using student's t -tests.

\section{Results}

A total of 120 questionnaire were distributed among the persons who were suffering from essential hypertension. Answers to 110 questionnaires were complete and 10 questionnaires were incomplete. The mean ages of the subjects were 56.7 years. Sample consisted of 91 males and 19 females. History of smoking was positive in $90 \%$ of the male subject, while history of tobacco consumption was positive in $64 \%$ of the male subjects however there were not any positive histories in female subjects. History of antihypertensive drug present in $94 \%$ subject. Blood pressure was higher than normal found at the time of questionnaires administration in $22 \%$ of the subjects although they were taking anti hypertensive drug.

Out of 110 people interviewed, 94\% said they were suffering from hypertension, $32 \%$ were suffering from diabetes mellitus along with hypertension and $2 \%$ were suffering from coronary heart disease with hypertension (Figure 1). Only $11 \%$ of the total subjects were aware of the normal values of blood pressure. About $62 \%$ of hypertensive subjects used to measure their blood pressure regularly. $94 \%$ of subjects said that blood pressure should be monitored regularly. Only $28 \%$ of hypertensive subject said that they have reduced salt intake to control hypertension and so many subjects were not aware whether salt intakes being reduced in patient of hypertension. Only $24 \%$ of subjects said that body weight has a co-relation with hypertension. About $76 \%$ of hypertensive subject did not know about co-relation between blood pressure and body weight. About $90 \%$ of subjects said that walking has important role in control of hypertension and body weight. Only $22 \%$ of respondents were aware that pickles and papad contain high content of salt and history of daily consumption of papad, pickles present in $68 \%$ subjects. Only $32 \%$ of respondents refused fruit consumption due to increased blood glucose level otherwise remaining $68 \%$ of 
Table I: Knowledge and practice values regarding questions represent in subjects

\begin{tabular}{lcc}
\hline Type & Follower & Not follower \\
\hline Knowledge of normal values of blood pressure & 11 & 99 \\
Regular check-up of blood pressure & 68 & 42 \\
Taking anti hypertensive drug & 94 & 16 \\
Restricted salt intake & 30 & 80 \\
Weight reduction & 26 & 84 \\
Fruit consumption & 75 & 35 \\
smoking & 82 & 09 \\
Tobacco consumption & 58 & 33 \\
walking & 99 & 11 \\
Yoga, meditation & 03 & 97 \\
\hline
\end{tabular}

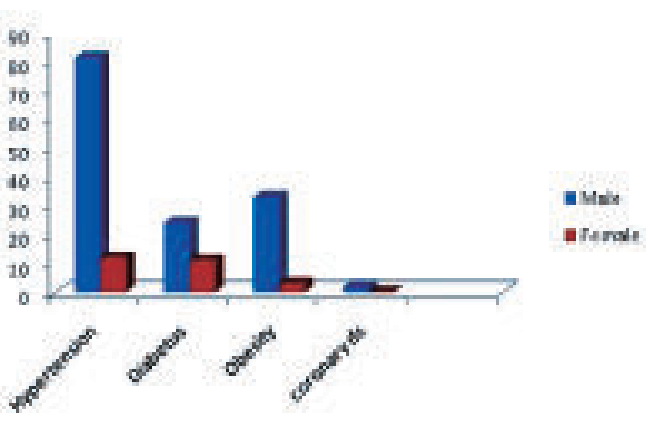

Figure 1: Percentage of male and female suffering from individual disease

hypertensive said that they take fruits in appropriate amount (Figure.2). Out of all, $74 \%$ of the respondents said that smoking and tobacco consumption should be reduced in patient of hypertension. About $92 \%$ of all respondents said that blood pressure can be controlled with drugs alone. Only $1 \%$ subject has use meditation to control hypertension.

\section{Discussion}

There is an increase in the prevalence of hypertension in past few years. Hypertension affects in the body systems and organs. Hypertension can be controlled with drugs along with some non-pharmacological measures. The present study assessed knowledge of non-

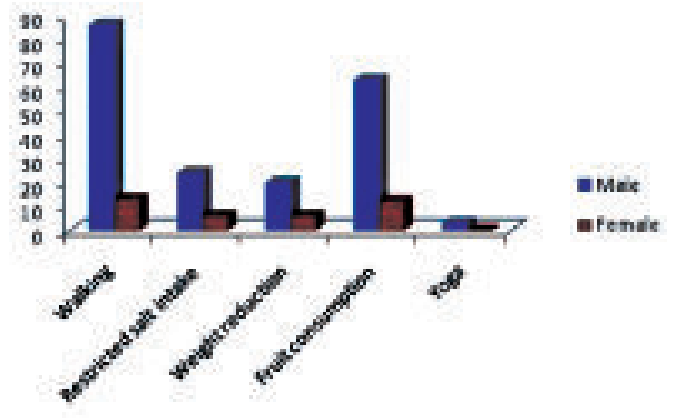

Figure 2: Percentage practice of factors for control of hypertension in both Male and Female

pharmacological measures to control hypertension in geriatric patients. About half of the study population was overweight. Family history of hypertension was present in 30 persons. All people spending sedentary life at present time. Half of the population was aware of co-relation between salt intake and blood pressure. ${ }^{8-11}$ Majority of population did not know about co-relation between blood pressure and body weight. ${ }^{12-13}$ The patients should be advised to stop smoking and tobacco consumption. Less salt intake should decrease blood pressure. Diet rich in fruit like bananas and vegetables like unsalted sunflower seeds, spinach, beans, baked white potato, soybeans etc. also helps in reducing blood pressure. Eating about 30 calories a day 
dark chocolate should prefer also for reduction of blood pressure without any adverse effect. It is not preferable for overweight people because chocolate is high in calories. Physical activity like daily walking reduces blood pressure and this is also the cause of the reduction in body weight. Impaired baro reflex sensitivity has been increasingly postulated to be one of the major causative factors of essential hypertension. A short period ( 3 months) of regular yogic practice for $1 \mathrm{hr} /$ day is effective in controlling blood pressure in such individuals. ${ }^{14}$

\section{Conclusion}

While knowledge and practice regarding body weight, smoking, and tobacco consumption remains satisfactory but regarding salt intake, fruit and vegetables' intake, role of yoga and exercise to correct hypertension remains poor in this study group. But further large scale studies need to be undertaken to know about true picture about knowledge of hypertension in old age persons.

\section{Authors affiliations}

1. *Debalina Sahoo, SBKSMIRC, Department of Physiology, Sumandeep Vidyapeeth, Vadodara$391760 \quad$ Gujarat, India Email: dev.sahoo90@gmail.com Tele: +918511939585

2. Harshida Gosai, SBKSMIRC, Department of Physiology, Sumandeep Vidyapeeth, Vadodara391760 Gujarat, India

3. Ujjwal Sahoo, Department of Pharmacy, Sumandeep Vidyapeeth, Vadodara-391760 Gujarat, India

4. J.M. Harsoda, SBKSMIRC, Department of Physiology, Sumandeep Vidyapeeth, Vadodara-391760 Gujarat, India

*For correspondance

\section{References}

1. Babatsikou F, Zavitsanou A. Epidemiology of hypertension in the elderly. Health Sci J 2010;4:24- 30.

2. Ellekjaer H, Holmen J, Vatten L. Blood pressure, smoking and body mass in relation to mortality from stroke and coronary heart disease in the elderly. A 10-year follow-up in Norway. Blood Press. 2001;10(3):156-63.

3. Menotti A, Lanti M, Kafatos A, Nissinen A, Dontas A, Nedeljkovic S, et al. The role of a baseline casual blood pressure measurement and of blood pressure changes in middle age in prediction of cardiovascular and all-cause mortality occurring late in life: a crosscultural comparison among the European cohorts of Seven Countries Study. J Hypertens 2004;22(9): 1683-1690.

4. Akl OA, Khairy AE, Abdel-Aal NM, Deghedi BS, Amer ZF. Knowledge, Attitude, Practice and Performance of Family Physicians Concerning Holistic Management of Hypertension. J Egypt Public Health Assoc. 2006;81(5-6):337-53.

5. Kalavathy MC, Thankappan KR , Sasma PS, Vasan RS. Prevalence, awareness, treatment and control of HTN in an elderly community -based sample in kerala, India. Natl Med J India. 2000;13(1):9-15.

6. WHO. Hypertension control.Technical Report Series No 862 , Genera: WHO 1996 : 3-20

7. Kannel WB. Blood pressure as a cardiovascular risk factor. JAMA. 1996;275(20):1571-6.

8. Patel CH, Mishra VR, Naik S, Jadeja JM., To study knowledge attitude and practice of nonpharmacological measures to control hypertension in geriatric population. Indian J Appl Basic Medi Scie 2012;14:34- 42.

9. He FJ, MacGregor GA. A comprehensive review on salt and health and current experience of worldwide salt reduction programmes. J Hum Hypertens. 2009;23(6):363-84.

10. World Health Organization. Reducing salt intake in populations: report of a WHO forum and technical meeting. WHO, 2007:1-60.

11. He FJ, MacGregor GA. Effect of modest salt reduction on blood pressure: a meta-analysis of randomized trials. Implications for public health. J Hum Hypertens. 2002;16(11):761-70.

12. Huang Z, Willett WC, Manson JE, Rosner B, et al. Body weight, weight change, and risk for hypertension in women. Ann Intern Med. 1998;128(2):81-8.

13. Gelber RP, Gaziano JM, Manson JE, Buring JE, Sesso HD. A prospective study of body mass index and the risk of developing hypertension in men. Am J Hypertens. 2007;20(4):370-7.

14. Jain AK. Text book of Physiology. $5^{\text {th }}$ Edition. New Delhi: Avichal Publishing Company. 2012;1:115-116. 